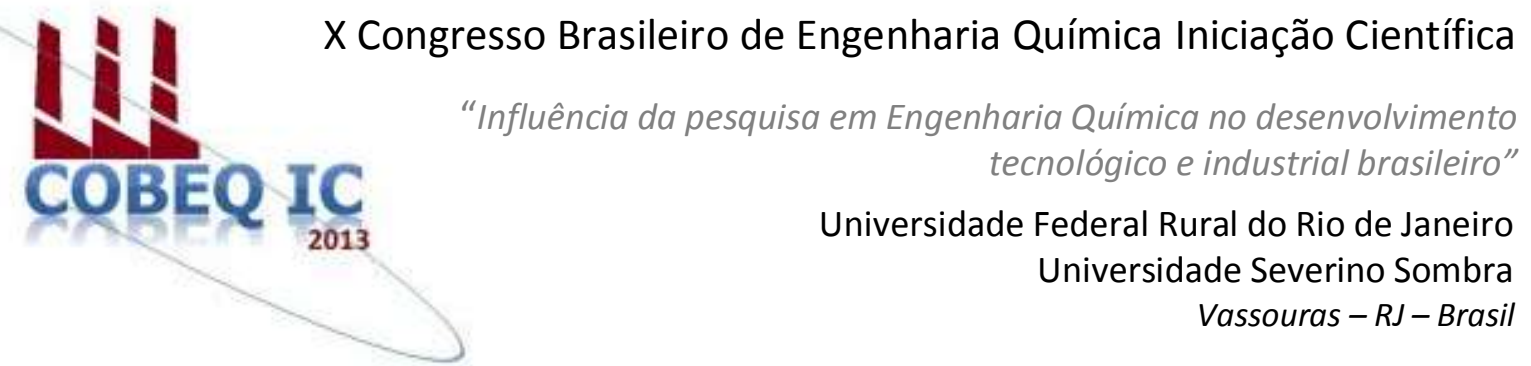

\title{
AVALIAÇÃO DO ESTADO TRÓFICO DA ÁGUA NA BARREIRA FLUTUANTE DE SANTANA EM PIRAÍ - RJ
}

\author{
E.S.PINTO ${ }^{1}$; C.S.SIQUEIRA ${ }^{2}$; R.M. NOGUEIRA ${ }^{3}$; O.S.PEREIRA ${ }^{4}$, C.S.S.PEREIRA ${ }^{5}$ \\ (1) Engenheira Ambiental - USS, ${ }^{(2)}$ Químico Industrial - USS, ${ }^{(3)}$ Tecnico em Quimica - CEFET, \\ ${ }^{(4)}$ Docente - DEMAT/ICE/UFRR, ${ }^{(5)}$ Docente - CECETEN/USS
}

Centro de Ciências Exatas, Tecnológicas e da Natureza - USS, Avenida Expedicionário Osvaldo de Almeida Ramos, 280 - Vassouras, RJ - CEP 27700-000 - e-mail: crisssbp@ hotmail.com

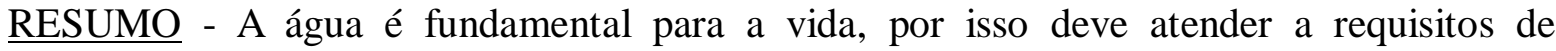
qualidade e quantidade adequadas ao consumo da população para garantir a manutenção da saúde e preservação do ecossistema. $\mathrm{O}$ objetivo deste trabalho foi analisar o estado trófico da água na barreira flutuante de Santana em Piraí - RJ, no período de seca, utilizando os cálculos de IET (Índice de Estado Trófico) a fim de identificar os principais indicadores de eutrofização, visando à conservação do ecossistema encontrado no rio. O rio Piraí caracteriza-se pelo elevado grau de impacto humano devido constante despejo de esgoto doméstico e atividades agropecuárias e apresenta uma acentuada proliferação de plantas aquáticas em toda sua extensão gerando altos níveis de nutrientes e cargas orgânicas em suas águas, impossibilitando a sua incorporação pelo sistema aquático e provocando assim, um desequilíbrio ecológico. Dentro deste contexto, buscou-se avaliar os parâmetros indicativos da qualidade da água próximo à barreira flutuante de Santana. Neste caso, torna-se fundamental a obtenção do $\mathrm{pH}$, da concentração de clorofila $a$ e do fósforo total. As amostragens foram realizadas em dois pontos da barreira. O valor do Índice de Estado Trófico (IET) foi calculado de acordo com os modelos propostos por Carlson (1977), Toledo (1983) e Lamparelli (2004), a fim de compará-los para uma melhor caracterização da qualidade da água.De acordo com as análises das amostras, o Índice proposto por Carlson (1977) classificou a água como Eutrófico, o Índice proposto por Toledo (1983) classificou a água entre Mesotrófico e Eutrófico e o Índice proposto por Lamparelli (2004) classificou a água entre Eutrófico e Supereutrófico.
\end{abstract}

Palavras chave: eutrofização, IET de Carlson, IET Modificado por Toledo, IET de Lamparelli, Rio Piraí, Barreira Flutuante de Santana

\section{INTRODUÇÃO}

A água é fundamental para a vida, por isso deve atender a requisitos de qualidade e quantidade adequadas ao consumo da população, com a finalidade de garantir a manutenção da saúde e preservar o ecossistema.

Segundo Esteves (1998), os grandes aglomerados urbanos próximos aos corpos d'água e os usos e ocupações da área de drenagem da bacia hidrográfica têm a potencialidade de alterar a qualidade da água.

No Brasil e na maioria dos países em desenvolvimento, a maior parte do esgoto bruto é lançada sem nenhum tratamento prévio nos cursos de água. Esse grande aporte de matéria orgânica poluente tem sido relatado 
como o principal responsável pela eutrofização de uma grande variedade de ambientes aquáticos, gerando preocupação crescente pelo alto grau de poluição e contaminação em que se encontram, atualmente, lagos e outros ambientes continentais (Tundisi, 2003).

\section{Eutrofização}

A eutrofização é o processo de crescimento acelerado de algas em rios, lagos e outros ambientes aquáticos, resultante do aumento da quantidade de nutrientes e/ou matéria orgânica nestes ecossistemas aquáticos. Esse aumento da quantidade de nutrientes acarreta na diminuição do volume total do ecossistema (Cruz e Braz, 2006), como mostra a figura 1 .

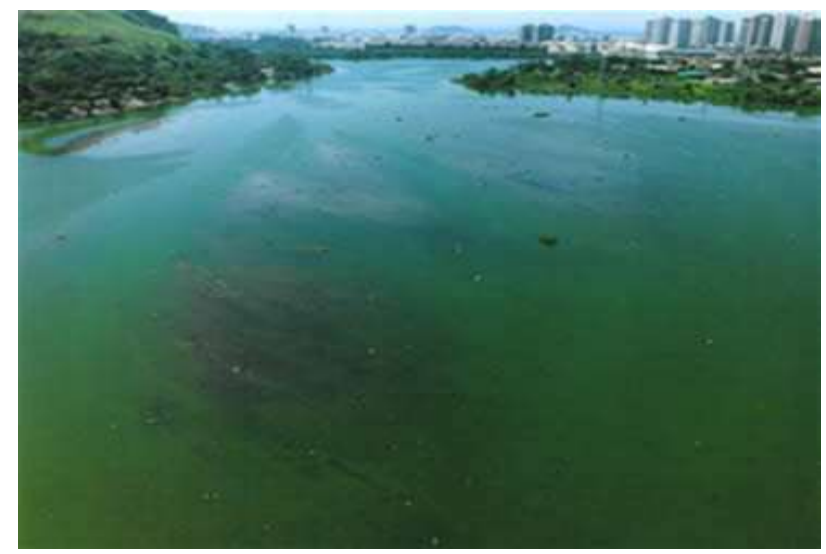

Figura 1 - Ambiente Aquático Eutrofizado

\section{Fósforo}

Segundo Esteves (1998) na maioria das águas continentais o fósforo é o principal fator limitante de sua produtividade. Além disso, tem sido apontado como o principal responsável pela eutrofização artificial destes ecossistemas.

\section{Clorofila $a$}

Segundo Passavante, et al. (1987/89), estudos sobre clorofila $a$ permitem avaliar o potencial de produção orgânica nestes ecossistemas, possibilitando um diagnóstico de seu estado de conservação.

\section{Avaliação da Eutrofização}

O estudo da eutrofização é de grande importância na avaliação da poluição hídrica, pois está relacionado à produção primária dos organismos vegetais (Sperling, 1996).

Segundo Oishi (1990) o estado trófico de um reservatório pode ser avaliado através de aspectos biológicos, físico-químicos, índices e modelos de carga.

Segundo CETESB (2008) os resultados correspondentes ao fósforo, IET(P), devem ser entendidos como uma medida do potencial de eutrofização, já que este nutriente atua como o agente causador do processo. A avaliação correspondente à clorofila a, IET(CL), por sua vez, deve ser considerada como uma medida da resposta do corpo hídrico ao agente causador, indicando de forma adequada o nível de crescimento de algas que tem lugar em suas águas.

\section{Análises Físico-Químicas}

\section{1- Fósforo Total}

As análises de fósforo total foram realizadas no Laboratório de uma Empresa Siderúrgica da região. A determinação de fósforo total foi feita em um erlenmyer de 150 $\mathrm{ml}$, onde foram adicionados $50 \mathrm{ml}$ da amostra e $5 \mathrm{ml}$ de ácido nítrico e levado a uma chapa elétrica de $150^{\circ} \mathrm{C}$ até redução de $5 \mathrm{ml}$ do volume, com cuidado para não secar, pois nesse caso o resultado será negativo. Após esta etapa foram adicionados mais $5 \mathrm{ml}$ de ácido nítrico e levados novamente a chapa até a redução de $3 \mathrm{ml}$. Após esfriamento, foi transferido para um balão de $50 \mathrm{ml}$. Após todo o procedimento, a amostra foi injetada no Aparelho ICP, que possui a curva para os parâmetros desejados.

\section{2- Clorofila $a$}

As análises de clorofila a foram realizadas no Laboratório de Química Ambiental da Universidade Sombra. A determinação de clorofila $a$ foi feita de acordo com Lorenzen (1967) através do método espectrofotométrico. A filtração da água para determinação de clorofila $a$ foi feita através de um sistema a vácuo, utilizando uma bomba elétrica com pressão a vácuo de 100 a 300 mmHg a fim de evitar a quebra das células fitoplanctonicas, com sistema de filtração para filtros de fibra de vidro. Após a filtração, os 
filtros foram guardados em papel alumínio, devidamente identificados com as estações amostrais e levados imediatamente para o congelador.

A extração de clorofila $a$ foi feita com solução $90 \%$ de acetona durante 24 horas a frio, através dos filtros de fibra de vidro com as amostras filtradas. Após este procedimento foi realizada a acidificação do extrato para análise das absorbâncias da amostra em espectrofotômetro.

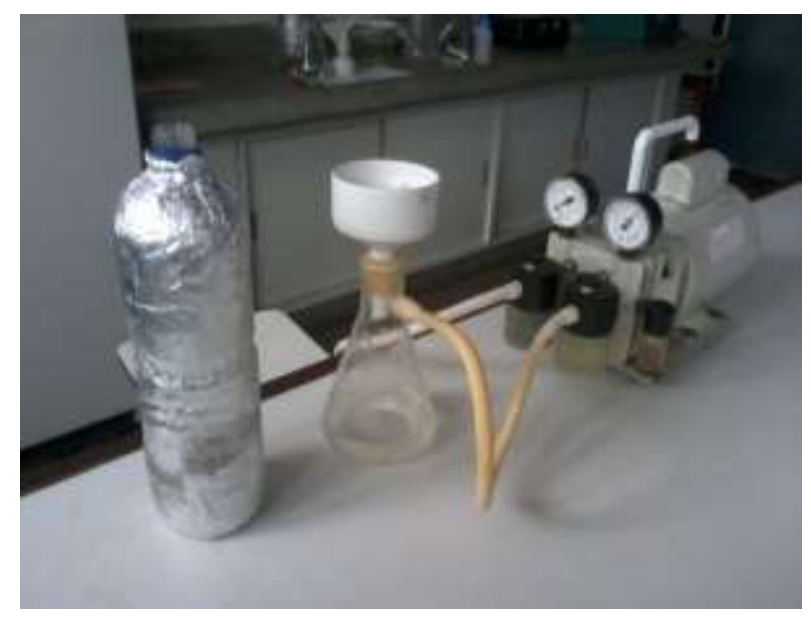

Figura 2: Análise de Clorofila $a$

Considerando que a qualidade da água referese a um padrão mais próximo possível do natural, torna-se imprescindível a determinação de parâmetros indicadores de qualidade (Branco, 1991).

\section{Resultados e Discussões}

\section{Análises de Fósforo Total e Clorofila a}

Em relação a concentração de fósforo total, os valores variaram entre 0,077 e 0,085 para a amostra 1 e entre 0,094 e 0,105 para a amostra 2. A concentração máxima de fósforo total permitida pela Resolução CONAMA 357/05 para Rios Classe II, em ambiente intermediário, com tempo de residência entre 2 e 40 dias, e tributários diretos de ambiente lêntico é de até $0,025 \mathrm{mg} / \mathrm{L}$.

Os valores de clorofila $a$ encontrados variaram entre $2,3 \mu \mathrm{g} / \mathrm{L}$ e $6,8 \mu \mathrm{g} / \mathrm{L}$. A concentração máxima de clorofila $a$ permitida pela Resolução CONAMA 357/05 para Rios Classe II é de até $30 \mu \mathrm{g} / \mathrm{L}$.

\section{Índice de Estado Trófico (IET)}

Foram realizados os cálculos de IET proposto por Carlson (1977), IET Modificado por Toledo Jr., et. al. (1983) e IET proposto por Lamparelli (2004), através dos resultados encontrados para fósforo total e clorofila $a$, para comparação dos resultados.

\section{Classificação Trófica quanto aos Índices}

A classificação trófica das amostras quanto aos Índices está disposto nas tabelas $1 \mathrm{e}$ 2.

\begin{tabular}{|c|c|c|}
\hline \multicolumn{3}{|c|}{$\begin{array}{c}\text { Classificação Trófica das Análises quanto aos } \\
\text { Índices para Amostra 1 (Setembro 2012) }\end{array}$} \\
\hline Parâmetros & IET $_{\mathbf{T}}$ & Classificação \\
\hline IET por Carlson & 53,72 & Eutrófico \\
\hline IET por Toledo & 49,07 & Mesotrófico \\
\hline IET por Lamparelli & 61,90 & Eutrófico \\
\hline
\end{tabular}

Tabela 1: Classificação Trófica das Análises quanto aos Índices para Amostra 1

Classificação Trófica das Análises quanto aos Índices para Amostra 2 (Novembro 2012)

\begin{tabular}{|c|c|c|}
\hline Parâmetros & IET $_{\mathbf{T}}$ & Classificação \\
\hline IET por Carlson & 59,03 & Eutrófico \\
\hline IET por Toledo & 54,54 & Eutrófico \\
\hline IET por Lamparelli & 65,17 & Supereutrófico \\
\hline
\end{tabular}

Tabela 2: Classificação Trófica das Análises quanto aos Índices para Amostra 1

\section{Outros Parâmetros Analisados}

Dentre os parâmetros analisados somente Fósforo total e Fosfato estavam acima do Limite Permitido pela Resolução na Amostra 1. Na Amostra 2, Fósforo total, Fosfato e o Fósforo solúvel estavam acima do Limite.

\section{Conclusões}

As concentrações de fósforo total encontradas nas amostras estudadas foram superiores ao limite estabelecido pela legislação. Já as concentrações de clorofila foram inferiores ao limite estabelecido.

Segundo LAMPARELLI (2004), num corpo hídrico, em que o processo de 
eutrofização encontra-se plenamente estabelecido, o estado trófico determinado pelo índice da clorofila $a$ coincidirá com o estado trófico determinado pelo índice do fósforo. Já nos corpos hídricos em que o processo esteja limitado por fatores ambientais, como a temperatura da água ou a baixa transparência, o índice relativo à clorofila $a$ irá refletir esse fato, classificando o estado trófico em um nível inferior àquele determinado pelo índice do fósforo.

Dessa forma, é possível afirmar que a água na Barreira Flutuante de Santana apresenta fatores limitantes do processo de eutrofização, pois os valores de IET para fósforo total são maiores que os valores de IET para clorofila a nos dois pontos de coleta.

\section{Considerações Finais}

As atividades agrícolas e urbanas no entorno do Rio Piraí, desde sua nascente até sua foz, influenciaram na qualidade da água, alterando negativamente os parâmetros clorofila $a$, ortofosfato e fósforo total.

Os valores encontrados de fósforo total indicam que o reservatório possui uma tendência a eutrofização e devem ser tomadas providências a fim de evitar o aumento da concentração de nutrientes.

\section{REFERÊNCIAS}

ANA. Agência Nacional de Águas. Portal da Qualidade das Águas. Indicadores de Qualidade - Índice de Estado Trófico. 2009.

BRANCO, S.M. (1991). Água e o Homem. In: PORTO, R.L.L. (org.) Hidrologia Ambiental. São Paulo: EDUSP/ABRH. p. 3-26.

BRASIL. Ministério do Meio Ambiente, Conselho Nacional de Meio Ambiente, CONAMA. Resolução CONAMA no 357 , de 17 de março de 2005.

BREZONIC,P.L. Planktonic communities in Florida soft water lakes of varying $\mathrm{pH}$. Canada. Journal Fish Aquatic, p. 46-56, 1976.
CARLSON, R. E. A trofic state index for lakes. Limnology and Oceanography. Vol. 22, p. 361-369. 1977.

CARVALHO, S. L. Eutrofização Artificial: Um Problema em Rios, Lagos e Represas. Artigo publicado no jornal Correio de Três Lagoas, 28 de Agosto de 2004.

\section{CETESB - Companhia Estadual de} Tecnologia de Saneamento Básico e Defesa do Meio Ambiente. Água: rios e reservatórios.

CETESB. Companhia de Tecnologia de Saneamento Ambiental, Governo do Estado de São Paulo, Secretaria do Meio Ambiente. Índices de Qualidade das Águas, Critérios de Avaliação da Qualidade dos Sedimentos e Indicador de Controle de Fontes. 2008. (Série Relatórios)

CETESB. Companhia de Tecnologia de Saneamento Ambiental, Governo do Estado de São Paulo, Secretaria do Meio Ambiente. Qualidade das Águas Interiores no Estado de São Paulo. Significado Ambiental e Sanitário das Variáveis de Qualidade das Águas e dos Sedimentos e Metodologias Analíticas e de Amostragem. 2009. (Série Relatórios apêndice $A$ )

CRUZ, M.J. \& BRAZ, R. (2000) A eutrofização dos sistemas aquáticos. Disponível em: <http://naturlink.sapo.pt/article.aspx?menuid= $\underline{4 \& \mathrm{cid}=874 \& \mathrm{bl}=1>}$. Portal Naturlink.pt. Acesso em 10 de setembro de 2012.

DUARTE, M.A.C.; CEBALLOS, O.; SUSANA, B.; ANNEMARIE, K.; MELO, H. N. M.; ARAÚJO, J. A. H.. Índice de Estado Trófico de Carlson (IET) aplicado em corpos aquáticos lênticos do nordeste do Brasil. In: CONGRESSO INTERAMERICANO DE INGENIERÍA SANITARIA Y AMBIENTAL, 26., Lima, 1998. Resumes... Lima: Associación Peruana de Ingenierya Sanitária y Ambiental - AIPS, AIDIS, p.1-5. 1998.

DUSSART, B.H. Sur quelques copepodes d'Amerique du Sud, IV. Revista Brasileira de Biologia, 44, p.255- 265. 1984. 
ESTEVES, F.A. Considerações sobre a aplicação da tipologia de lagos temperados e lagos tropicais. Acta Limnológica Brasiliensia. 2:3 - 28. 1988.

ESTEVES, F. A. Lagoas Costeiras: origem, funcionamento e possibilidades de manejo. In: Esteves, F. A., Ecologia das Lagoas Costeiras do Parque Nacional da Restinga de Jurubatiba e do Município de Macaé - RJ. Núcleo de Pesquisas Ecológicas de Macaé (NUPEM). Vol., RJ, Ed UFRJ. 63-87. 1998.

FIA, R.; MATOS, A.T.; CORADI, P.C.; PEREIRA-RAMIREZ, O. Estado trófico da água na bacia hidrográfica da Lagoa Mirim, RS, Brasil. Ambi-Agua, Taubaté, v.4, n.1, p.132-141 2009.

Gonçalves, E.F., Vasconcellos, J.M., Pinese, J.P.P., Correa, G.T., França, V., Souza Filho, E.E.. Levantamentos Preliminares da Saúde Coletiva com Base na Geoquímica das Águas Superficiais do Entorno das Ilhas Mutum e Porto Rico, Alto Rio Paraná (PR - BRASIL). 2009.

GTZ/SEAMA. Relatório de qualidade de água. Microbacia do Rio Jacaraípe - Vitória - ES. Governo do Estado para assuntos do Meio Ambiente. Convênio Cooperação Técnica Brasil / Alemanha. 2000.

HENRY, R., TUNDISI, J.G., CURI, P.R. Fertilidade Potencial em Ecossistemas Aquáticos: Estimativa através de Experimentos de Eutrofização Artificial. Ciência e Cultura. v.35, n.6, p.789-800, 1983.

KARABIN，A.; EJSMONT-KARABIN，J.; KORNATOWSKA, R. Eutrophication process in a shallow, macrophyte-dominated lakefactors influencing zooplankton structure and density in Lake Luknajno (Poland). Hydrobiologia, Netherlands, 342-343: 401409. 1997.

LAMPARELLI, M. C. Grau de trofia em corpos d'água do estado de São Paulo: avaliação dos métodos de monitoramento. Tese (Doutorado em Ecologia Aplicada) -
Universidade de São Paulo, Instituto de Biociências, São Paulo, 2004.

LEAL, P.R. Avaliação de Indicadores do Estado Trófico de uma Lagoa Costeira: Lagoa Jacuném em Serra - ES. Vitória, Espírito Santo. 2006.

LORENZEN, C. J. Determination of chlorophyll and phaeo-pigments: spectrophotometric equations. Limnology and Oceanography. Vol. 12, p. 343-346. 1967.

MARGALEFT, R. Limnologia. Barcelona: Omega, 1983.

MELlo, A. G. B. Programa de PósGraduação em Tecnologia de Processos Químicos e Bioquímicos. Influência da Deformação Plástica na Corrosão de Aço Cabrono, Aço Inoxidável e Cobre em Sistemas de Resfriamento. 2008.

MOTA, S. Introdução à Engenharia Ambiental. 4.ed. Rio de Janeiro: Abes,.388p. 2006.

NOGUEIRA, V. P. Q. Qualidade da água em lagos e reservatórios. In: Hidrologia Ambiental, Coleção ABRH de Recursos Hídricos (Branco et al.) Vol. 3. São Paulo, Ed. da Universidade de São Paulo, p.p. 165200. 1991.

OISHI, M.K. Determinação do Potencial Trófico das Águas dos Componentes da Bacia Hidrográfica da Represa do Lobo (ItirapinaSP) através de Ensaio Algal. Tese (Dissertação de Mestrado em Engenharia Hidráulica e Sanitaria), Escola de Engenharia de São Carlos, Universidade de São Paulo. São Carlos. 131p. 1990.

PASSAVANTE, J. Z. O. Estudo ecológico da região de Itamaracá, Pernambuco- Brasil XIX Biomassa do nano e microfitoplâncton do Canal de Santa Cruz. Trabalhos Oceanográficos da Universidade Federal de Pernambuco. Recife, 1981.

PINTO-COELHO, R.M. Effects of eutrophication on seasonal patterns of mesozooplankton in a tropical reservoir: a 4- 
year study in Pampulha Lake, Brazil. Freshwater Biology, London, 40: 159-173. 1998.

PIVELI, Roque Passos. Qualidade das águas e poluição: aspectos físico-químicos: Ferro, Manganês e Metais Pesados em águas. São Paulo: ABES, 2006.

POMPÊO, M. L. M. Macrófitas aquáticas e perifíton aspectos ecológicos e metodológicos. São Carlos, SP. Ed. RiMa, p.7-21. 2003.

ROUND, F. E. Biologia das algas. 2. ed. Rio de janeiro: Guanabara Dois, 1973.

Smith, V.H. \& Schindler, D.W. Eutrophication science: where do we go from here? Trends in Ecology and Evolution 24: 201-207. 2009.

SILVA, A.A.M.J.; ROSA, A.H.; MORETTI, J.P.; DUARTE, J.G.C.; PITTA, J.A.B. Avaliação Sazonal e Espacial do Estado Trófico do Reservatório de Itupararanga - SP. Campus de Sorocaba - Departamento de Engenharia Ambiental. São Paulo, 2009

SILVEIRA, C.; Rosa, L.; MEES, J.B.R.; BORTOLI, M.M. Determinação do Índice de Estado Trófico de um Manancial Receptor de Efluentes de Estação de Tratamento de Esgoto.

II Congresso Brasileiro de Gestão Ambiental. Londrina, Paraná. 2009.

SILVA, S.C.; NISHIMURA, P.Y.; PÔMPEO, M.L.M; CARLOS, V.M. Caracterização Limnológica das Águas Superficiais do Reservatório Billings em São Paulo - SP. VIII Congresso de Ecologia do Brasil. Caxambu, Minas Gerais. 2007.

SOUZA, D.A. Bacia do Riberão e Represa do Lobo: Bases Ecológicas para o Planejamento Regional, Manejo e Conservação. Tese (Dissertação de Doutorado em Engenharia Civil) - Escola de Engenharia de São Carlos , Universidade de São Paulo. São Carlos158 p. 1993.

SPERLING, E. Avaliação do Estado Trófico de Lagos e Reservatórios Tropicais. Bio Engenharia Sanitária e Ambiental. p. 68-71, 1996.
TIETENBERG, T.H. (1994). Administrando a transição para um desenvolvimento sustentável: $\mathrm{O}$ papel dos incentivos econômicos. In: MAY, P.H. \& MOTTA, R.S. (orgs.). Valorando a natureza: a análise econômica para o desenvolvimento sustentável. Rio de Janeiro. Ed. Campos. p. 93-109.

TOLEDO, A.P.; TALARICO, M.; CHINEZ, S.J.; AGUDO, E.G. A aplicação de modelos simplificados para a avaliação do processo da eutrofização em lagos e reservatórios tropicais.

Congresso Brasileiro de Engenharia Sanitária e Ambiental. Balneário Camboriú, Santa Catarina. 1983.

TUNDISI, J.G. A crise da água: eutrofização e suas consequências. In. TUNDISI, J.G. Água no século XXI: enfrentando a escassez. Rima, IIE, São Carlos. 247 p. 2003.

UNEP-IETC. Planejamento e gerenciamento de lagos e represas: uma abordagem integrada ao problema de eutrofização. Programa das Nações Unidas para o Meio Ambiente Instituto Internacional de Ecologia, São Carlos, 385 p. (edição em português). 2001.

WETZEL, R.G. Limnologia. Fundação Calouste Gulbenkian. 1011 p. 1993. 